\title{
Visualization of higher-level receptive fields in a hierarchical model of the visual system Christian Hinze $^{* 1}$, Niko Wilbert ${ }^{1,2}$ and Laurenz Wiskott ${ }^{1,2}$
}

\author{
Address: ${ }^{1}$ Institute for Theoretical Biology, Humboldt University, 10115 Berlin, Germany and ${ }^{2}$ Bernstein Center for Computational Neuroscience, \\ Humboldt University, 10099 Berlin, Germany \\ Email: Christian Hinze* - ChristianHinze@web.de \\ * Corresponding author
}

from Eighteenth Annual Computational Neuroscience Meeting: CNS*2009

Berlin, Germany. 18-23 July 2009

Published: I 3 July 2009

BMC Neuroscience 2009, I0(SuppI I):PI58 doi:I0.II86/I47|-2202-I0-SI-PI58

This abstract is available from: http://www.biomedcentral.com//47I-2202/I0/SI/PI58

(c) 2009 Hinze et al; licensee BioMed Central Ltd.

Early visual receptive fields have been measured extensively and are fairly well mapped. Receptive fields in higher areas, on the other hand, are very difficult to characterize, because it is not clear what they are tuned to and which stimuli to use to study them. Early visual receptive fields have been reproduced by computational models. Slow feature analysis (SFA), for instance, is an algorithm that finds functions that extract most slowly varying features from a multi-dimensional input sequence [1]. Applied to quasi-natural image sequences, i.e. image sequences derived from natural images by translation, rotation and zoom, SFA yields many properties of complex cells in V1 [2].

A hierarchical network of SFA units learns invariant object representations much like in IT [3]. These successes suggest that units of intermediate layers in the network might share properties with cells in V2 or V4. The goal of this project is therefore to develop techniques to visualize and characterize such units to understand how cells in V2/V4 might work. This is nontrivial because the units are highly nonlinear. The algorithm is gradient-based and applied in a cascade within the network. We start with a natural image patch as an input, which then gets optimized by gradient ascent to maximize the output of one particular unit. Figure 1 shows such optimal stimuli for units in the first $(\mathrm{a}, \mathrm{b})$ and the second layer $(\mathrm{c}, \mathrm{d})$. The latter can be associated with cells in V2/V4. We plan to extend this to higher layers and larger receptive fields and will also develop techniques to visualize the invariances of the units, i.e. those variations to the input that have little effect on the unit's output. The long-term goal is to provide a good stimulus set for characterizing cells in V2/V4.

\section{References}

I. Wiskott L, Sejnowski TJ: Slow feature analysis: Unsupervised learning of invariances. Neural Computation 2002, 14:715-770.

2. Berkes $P$, Wiskott $L$ : Slow feature analysis yields a rich repertoire of complex cell properties. J Vision 2005, 5:579-602.

3. Franzius $M$, Wilbert $N$, Wiskott $L$ : Invariant object recognition with slow feature analysis. Proc 18th Int'l Conf on Artificial Neural Networks 2008:96I-970. 

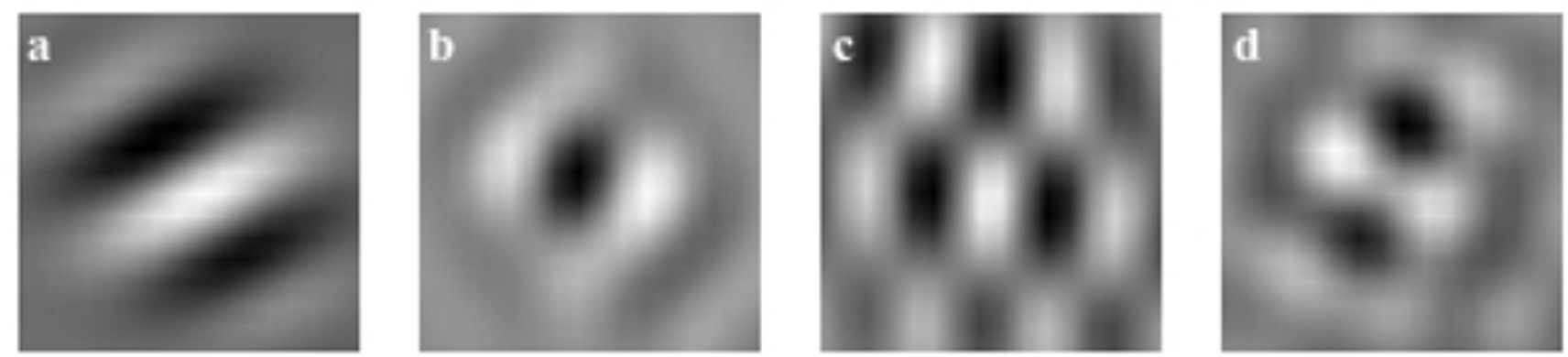

\section{Figure I}

Optimal stimuli of units in the first layer $(a, b)$ and the second layer $(c, d)$ of a hierarchical SFA network optimized for slowness and trained with quasi-natural image sequences.

Publish with Bio Med Central and every scientist can read your work free of charge

"BioMed Central will be the most significant development for disseminating the results of biomedical research in our lifetime. "

Sir Paul Nurse, Cancer Research UK

Your research papers will be:

- available free of charge to the entire biomedical community

- peer reviewed and published immediately upon acceptance

- cited in PubMed and archived on PubMed Central

- yours - you keep the copyright 